atherosclerotic plaques, systemic lupus erythematosus and healthy donors. Atherosclerosis. 2018;268:36-48.

[4] Fiskesund R, Steen J, Amara K, Murray F, Szwajda A, Liu A, Douagi I, Malmstrom $\mathrm{V}$ and Frostegard J. Naturally occurring human phosphorylcholine antibodies are predominantly products of affinity-matured B cells in the adult. J Immunol. 2014;192:4551-9.

Disclosure of Interests: : Divya Thiagarajan: None declared, Roland Fiskesund: None declared, Johanna Steen: None declared, Mizanur Rahman: None declared, Susanna Lundström: None declared, Johan Frostegård Grant/ research support from: Unconditional competitive grant from Amgen, related only to PCSK9, not the topic of this abstract

DOI: 10.1136/annrheumdis-2020-eular.5779

\section{THU0231 IL-2 DRIVES THE CONVERSION OF T FOLLICULAR HELPER TO T FOLLICULAR REGULATORY CELLS THROUGH EPIGENETIC MODIFICATION IN SYSTEMIC LUPUS ERYTHEMATOSUS}

$\underline{\text { H. Hao }}^{1,2}$, S. Nakayamada ${ }^{1}$, Y. Kaoru ${ }^{1}$, N. Ohkubo ${ }^{1}$, S. Iwata ${ }^{1}$, Y. Tanaka ${ }^{1}$. ${ }^{1}$ University of Occupational and Environmental Health, School of Medicine, First Department of Internal Medicine, Kitakyushu, Japan; ${ }^{2}$ The Fourth Hospital of Hebei Medical University, Department of Immuno-Oncology, Shijiazhuang, China

Background: Systemic lupus erythematosus (SLE) is a complex polygenic autoimmune disease characterized by immune-system aberrations. Among several types of immune cells, T follicular helper (Tfh) cells promote autoantibody production, whereas $T$ follicular regulatory (Tfr) cells suppress Tfh-mediated antibody responses. ${ }^{(1)}$

Objectives: To identify the characteristics of Tfr cells and to elucidate the mechanisms of conversion of Tfh cells to Tfr cells, we probed the phenotype of $\mathrm{T}$ helper cells in patients with SLE and underlying epigenetic modifications by cytokine-induced signal transducer and activators of transcription (STAT) family factors.

Methods: Peripheral blood mononuclear cells from SLE patients $(n=44)$ and healthy donors $(\mathrm{HD} ; \mathrm{n}=26)$ were analyzed by flow cytometry. Memory Tfh cells were sorted and cultured under stimulation with $\mathrm{T}$ cell receptor and various cytokines. Expression of characteristic markers and phosphorylation of STATs (p-STATs) were analyzed by flow cytometry and quantitation PCR. Histone modifications were evaluated by chromatin immunoprecipitation.

Results: The proportion of $\mathrm{CXCR}^{+}{ }^{+} \mathrm{FoxP} 3^{+} \mathrm{Tfr}$ cells in $\mathrm{CD} 4^{+} \mathrm{T}$ cells tended to increase $(2.1 \%$ vs $1.7 \%, p=0.17)$; however, that of $C D 4^{+} C D 45 R A-F o x P 3{ }^{\text {hi }}$ activated Tfr cells in Tfr cells was decreased $(4.8 \%$ vs $7.1 \%, p<0.05)$, while CD $4^{+}$CD45RA-FoxP3 ${ }^{\text {low }}$ non-suppressive $\mathrm{Tfr}$ cells was increased $(50.1 \%$ vs $38.2 \%, \mathrm{p}<0.01)$ in SLE compared to HD. The percentage of PD- $1^{\mathrm{hi}}$ activated Tfh cells was significantly higher in SLE compared to HD (15.7\% vs $5.9 \%$, $\mathrm{p}<0.01)$. Furthermore, active patients had a higher ratio of activated $\mathrm{Tfh} / \mathrm{Tfr}$ cells compared to inactive patients. In vitro study showed that IL-2, but not other cytokines such as TGF- $\beta 1$, IL-12, IL-27, and IL-35, induced the conversion of memory Tfh cells to functional Tfr cells characterized by $\mathrm{CXCR} 5^{+} \mathrm{B}$ $\mathrm{cl}^{+}{ }^{+}$oxp $^{\text {hi }}$ pSTAT $^{+}$pSTAT $^{+}$cells. The loci of FOXP3 at STAT binding sites were marked by bivalent histone modifications. After IL-2 stimulation, STAT5 directly bound on FOXP3 gene loci accompanied by suppressing H3K27me3. Finally, we found that serum level of IL-2 was decreased in SLE and that stimulation with IL-2 suppressed the generation of $\mathrm{CD} 38^{+} \mathrm{CD} 27^{+} \mathrm{B}$ cells by ex vivo coculture assay using Tfh cells and B cells isolated from human blood.

Conclusion: Our findings indicated that the regulatory function of Tfr cells is impaired due to the low ability of IL-2 production and that IL-2 restores the function of Tfr cells through conversion of Tfh cells to Tfr cells in SLE. Thus, the reinstatement of the balance between Tfh and $\mathrm{Tfr}$ cells will provide important therapeutic approaches for SLE.

References:

[1] Deng J, Wei Y, Fonseca VR, et al. T follicular helper cells and T follicular regulatory cells in rheumatic diseases. Nat Rev Rheumatol. 2019; 15 (8): 475-90.

Disclosure of Interests: : He Hao: None declared, Shingo Nakayamada Grant/ research support from: Mitsubishi-Tanabe, Takeda, Novartis and MSD, Speakers bureau: Bristol-Myers, Sanofi, Abbvie, Eisai, Eli Lilly, Chugai, Asahi-kasei and Pfizer, Yamagata Kaoru: None declared, Naoaki Ohkubo: None declared, Shigeru Iwata: None declared, Yoshiya Tanaka Grant/research support from: Asahi-kasei, Astellas, Mitsubishi-Tanabe, Chugai, Takeda, Sanofi, Bristol-Myers, UCB, Daiichi-Sankyo, Eisai, Pfizer, and Ono, Consultant of: Abbvie, Astellas, Bristol-Myers Squibb, Eli Lilly, Pfizer, Speakers bureau: Daiichi-Sankyo, Astellas, Chugai, Eli Lilly, Pfizer, AbbVie, YL Biologics, Bristol-Myers, Takeda, Mitsubishi-Tanabe, Novartis, Eisai, Janssen, Sanofi, UCB, and Teijin

DOI: 10.1136/annrheumdis-2020-eular.651

\section{THU0232 INTERFERON SIGNATURE IN LUPUS KIDNEY IS} CORRELATED WITH REMISSION WITHIN 56 WEEKS

M. Kanda ${ }^{1,2,3}$, T. Tsuji ${ }^{4}$, M. Mukai ${ }^{5}$, H. Takahashi $^{2}$, T. Atsumi ${ }^{3}$, N. Hübner ${ }^{1}$. ${ }^{1}$ Max Delbrück Center for Molecular Medicine in the Helmholtz Association (MDC), Cardiovascular and Metabolic Sciences, Berlin, Germany; ${ }^{2}$ Sapporo Medical University, Department of Rheumatology and Clinical Immunology, Sapporo, Japan; ${ }^{3}$ Hokkaido University Graduate School of Medicine, Division of Rheumatology, Endocrinology and Nephrology, Sapporo, Japan; ${ }^{4}$ Sapporo City General Hospital, Department of Pathology, Sapporo, Japan; ${ }^{5}$ Sapporo City General Hospital, Department of Rheumatology and Clinical Immunology, Sapporo, Japan

Background: Activation of the type I interferon (IFN) pathway has been implicated in the initiation of systemic lupus erythematosus(SLE) and most SLE patients show increased expression of IFN-regulated genes in peripheral blood mononuclear cells or whole blood. However, the IFN signature in lupus kidney is not well examined especially at single cell resolution.

Objectives: To clarify the significance of the IFN signature in lupus kidney at single cell resolution

Methods: 18 lupus kidney (LN) and 34 transplanted kidney (KTx) samples were included in the study. Residual frozen kidney biopsies were collected after clinical diagnosis. The tissue from one donor was split into two. One portion was used for total RNA-Seq (tRNA-Seq) by SMARTer Stranded Total RNA-Seq Kit v2 - Pico Input Mammalian (Takara/Clontech). The rest was used for single nucleus RNA-Seq (snRNA-Seq) using Chromium Single Cell 3' Reagent Kits v3 (10x Genomics) ( $7 \mathrm{LN}$ and $17 \mathrm{KTx}$ ). For the tRNA-Seq, the sequence reads were aligned to Ensembl genome annotation (Ens93) by STAR and the aligned reads were counted by htseq. IFN score of TRNA-Seq was calculated using the reported method [1] per each module (M1.2, M3.4 and M5.12). For the snRNA-Seq, the sequenced reads were processed on the standard pipeline of CellRanger (10x Genomics) and the data was visualized using Seurat. IFN score of snRNA-Seq was computed by the method reported by Arazi A, et al [2]

Clinical outcomes of LN were examined on the medical records retrospectively and the clinical remission in 56 weeks for LN was defined as a urinary protein/ creatinine ratio less than $0.5 \mathrm{~g} / \mathrm{gCr}$.

Results: $11 \mathrm{LN}$ had clinical remission and $7 \mathrm{LN}$ showed non remitted disease within 56 weeks after the biopsy. There were no statistical significance co-variants such as age, gender and WHO class in pathology. IFN score of M1.2 M3.4 and M5.12 were significantly increased in LN with remission within 56 weeks (median 0.773 vs $0.659,0.595$ vs 0.243 and 0.415 vs 0.100 : $p$-value $0.03,0.01$ and 0.02 [Wilcox rank-test]) in tRNA-Seq. In the snRNA-Seq, the lupus kidney with low IFN score showed restricted IFN signature in the endothelial cells mainly, which can be detected even in the controls, but those with high IFN score indicated broadly spread IFN signature among all of the cell types.

Conclusion: LN with high IFN score in kidney tissue is correlated with remission within 56 weeks. LN with low IFN score showed IFN signature restricted to endothelial cells but those with a higher IFN score revealed broadly affected cell types with IFN signature. These results suggest that the IFN signature of LN may start from endothelial cells and then spread to the whole kidney.

\section{References:}

[1] Chiche L, Jourde-Chiche N, Whalen E, et al. Modular Transcriptional Repertoire Analyses of Adults With Systemic Lupus Erythematosus Reveal Distinct Type I and Type II Interferon Signatures. Arthritis \& Rheumatology 2014;66:1583-95. doi: 10.1002/art.38628

[2] Arazi A, Rao DA, Berthier CC, et al. The immune cell landscape in kidneys of patients with lupus nephritis. Nat Immunol 2019;20:902-14

doi:10.1038/s41590-019-0398-x

Disclosure of Interests: : Masatoshi Kanda: None declared, Takahiro Tsuji: None declared, Masaya Mukai: None declared, Hiroki Takahashi: None declared, Tatsuya Atsumi Grant/research support from: Eli Lily Japan K.K., Alexion Pharmaceuticals, Inc., Bristol-Myers Squibb Co., AbbVie Inc., Daiichi Sankyo Co., Ltd., Pfizer Inc., Chugai Pharmaceutical Co., Ltd., Mitsubishi Tanabe Pharma Co., Astellas Pharma Inc., Consultant of: Gilead Sciences, Inc., Eli Lilly Japan K.K., UCB Japan Co. Ltd., AbbVie Inc., Daiichi Sankyo Co., Ltd., Pfizer Inc., Chugai Pharmaceutical Co., Ltd., Speakers bureau: Eli Lilly Japan K.K., UCB Japan Co. Ltd., Bristol-Myers Squibb Co., AbbVie Inc., Eisai Co. Ltd., Otsuka Pharmaceutical Co., Ltd., Daiichi Sankyo Co. Ltd., Pfizer Inc., Chugai Pharmaceutical Co., Ltd., Mitsubishi Tanabe Pharma Co., Takeda Pharmaceutical Co., Ltd., Astellas Pharma Inc., Norbert Hübner: None declared

DOI: 10.1136/annrheumdis-2020-eular.3113 